\title{
A Comprehensive Review of Meningococcal Disease Burden in India
}

\author{
Ashok Kumar Dutta $\cdot$ Subramanian Swaminathan · Veronique Abitbol \\ Shafi Kolhapure (D) - Sripriya Sathyanarayanan
}

Received: May 26, 2020 / Published online: July 23, 2020

(C) The Author(s) 2020

\begin{abstract}
Introduction: Meningococcal disease caused by Neisseria meningitidis has a high case fatality rate. Of 12 distinct serogroups, A, B, C, W-135 $(\mathrm{W})$ and $\mathrm{Y}$ cause the majority of infections. The meningococcal disease burden and epidemiology in India are not reliably known. Hence, we performed a narrative review with a systematically conducted search to summarize information on meningococcal disease burden and epidemiology and vaccination recommendations for meningococcal disease in India.
\end{abstract}

Digital Features To view digital features for this article go to https://doi.org/10.6084/m9.figshare.12613760.

Electronic supplementary material The online version of this article (https://doi.org/10.1007/s40121020-00323-4) contains supplementary material, which is available to authorized users.

\section{A. K. Dutta}

Department of Pediatrics, Indraprastha Apollo

Hospitals, New Delhi, India

S. Swaminathan

Department of Infectious Diseases, Gleneagles

Global Hospitals, Chennai/Bangalore, India

V. Abitbol

Global Medical Affairs, GSK, Rueil-Malmaison, France

S. Kolhapure · S. Sathyanarayanan $(\bowtie)$

Medical Affairs Department, GSK, Mumbai, India

e-mail: sripriya.x.sathyanarayanan@gsk.com
Methods: A search of Medline and Embase databases was undertaken to identify relevant publications published in the last 25 years.

Results: Results from 32 original publications, 11 of which were case reports, suggest a significant burden of meningococcal disease and related complications. Meningococcal disease is increasingly reported among adolescents and adults, and large outbreaks have been reported in this population. Meningococcal disease in India is caused almost exclusively by serogroup $\mathrm{A}$; serogroups $\mathrm{B}, \mathrm{C}, \mathrm{W}$ and $\mathrm{Y}$ have also been documented. Meningococcal disease burden data remain unreliable because of limited disease surveillance, insufficient laboratory capacity, misdiagnosis and prevalence of extensive antibiotic use in India. Lack of access to healthcare also increases under-reporting, thus bringing the reliability of the data into question. Conjugate meningococcal vaccines are being used for disease prevention by national governments and immunization programs globally. In India, meningococcal vaccination is recommended only for certain high-risk groups, during outbreaks and for international travelers such as Hajj pilgrims and students pursuing studies abroad.

Conclusion: Meningococcal disease is prevalent in India but remains grossly underestimated and under-reported. Available literature largely presents outbreak data related to serogroup A disease; however, non-A serogroup disease cases have been reported. Reliable epidemiologic data 
are urgently needed to inform the true burden of endemic disease. Further research into the significance of meningococcal disease burden can be used to improve public health policy in India.

A comprehensive review of meningococcal disease burden in India

Ashok Kumar Dutta, Subramanian Swaminathan, Veronique Abitbol, Shafi Kolhapure, Sripriya Sathyanarayanan

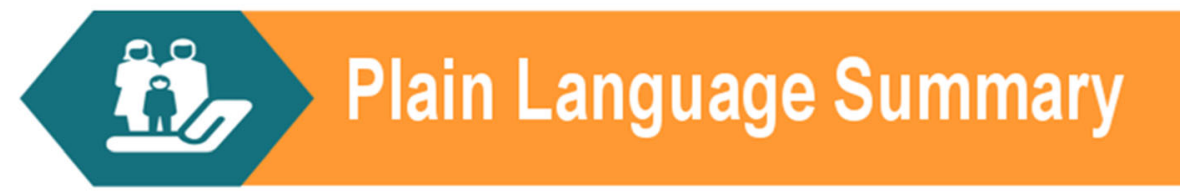

\section{What is the context?}

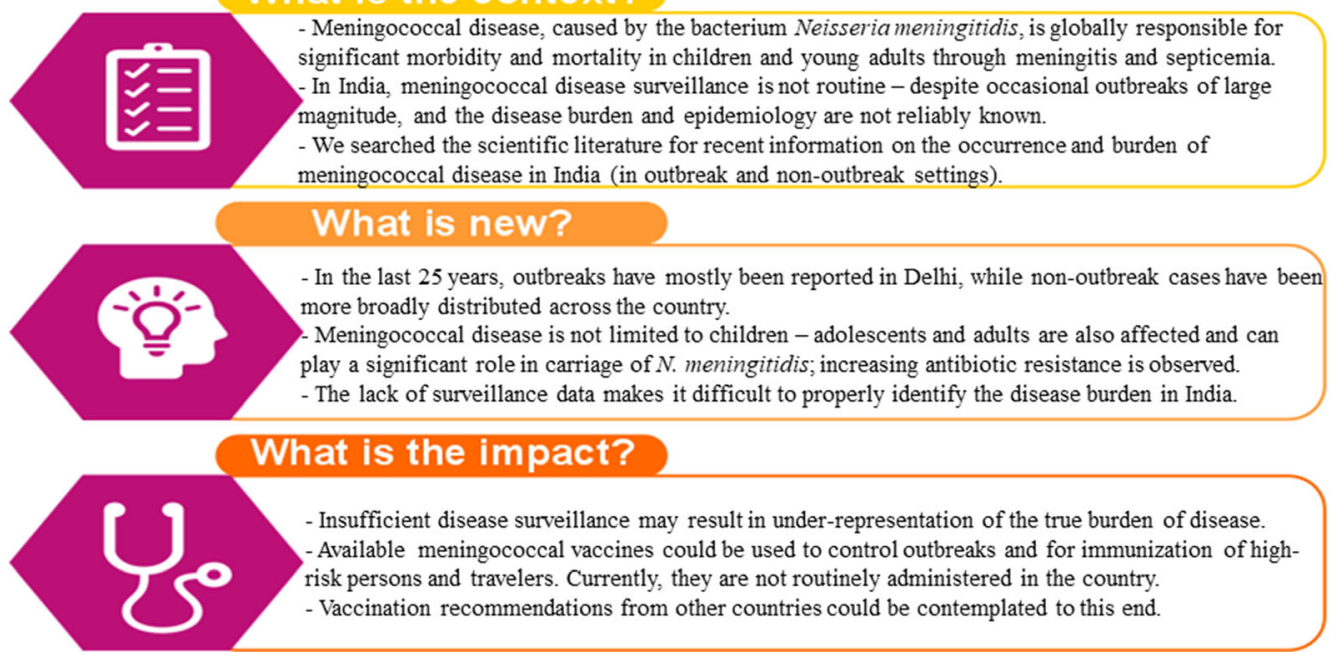

Fig. 1 Plain language summary

Keywords: Adolescents; Adults; Children; Immunization; India; MenACWY vaccine; Meningococcal disease; Mortality; Outbreaks; Under-reporting

\section{Key Summary Points}

\section{Why carry out this study?}

Invasive meningococcal disease is a lifethreatening disease that can mimic mild respiratory illness in the early stages but can rapidly progress to death within 24-48 h.

The disease burden and epidemiology of meningococcal disease in India are not reliably known.
In this comprehensive review with a systematically conducted literature search, we summarize information on the epidemiology, disease burden and vaccination recommendations for meningococcal disease in India.

\section{What was learned from this study?}

In the last 25 years, meningococcal disease has not been limited to the pediatric population (cases were often documented in the adolescent and adult population).

Data on the burden of meningococcal disease show that the country is susceptible to outbreaks. 
Data on the burden of endemic disease remains unreliable because of limited disease surveillance, insufficient laboratory capacity, misdiagnosis and extensive antibiotic use, which is prevalent in India.

Outbreaks of meningococcal disease in India are most commonly caused by serogroup A. Other serogroups such as B, $\mathrm{C}, \mathrm{W}$ and $\mathrm{Y}$ have also been reported in the non-outbreak studies.

In India, there is no national policy on routine meningococcal vaccination to control the disease.

\section{INTRODUCTION}

Meningococcal disease caused by the gramnegative bacteria Neisseria meningitidis ( $N$. meningitidis) is a leading cause of meningitis and highly fatal septicemia globally $[1,2]$. It is an unpredictable disease, which can easily be misdiagnosed at an early stage with non-specific symptoms such as flu-like symptoms. Meningococcal disease is associated with rapid onset, significant risk of death with a high fatality rate (up to 50.0\%) in untreated cases and high frequency (10.0-20.0\%) of severe sequelae causing brain damage, hearing loss or other such long-term disability [3]. The bacteria $N$. meningitidis only infect humans and are transmitted from one person to another through droplets of respiratory or throat secretions via carriers through close contacts [3]. The bacteria can be carried in the upper respiratory tract of humans, and research suggests that $1.0-10.0 \%$ of the population carries $N$. meningitidis in their throat at any given time [3]. Published literature suggests that carriage rates may be higher (up to 90.0\%) in epidemic situations and in confined populations such as military recruits and people on pilgrimages [4-8]. Meningococci are categorized into 12 distinct serogroups, of which only 6, namely A, B, C, $\mathrm{W}-135(\mathrm{~W}), \mathrm{X}$ and $\mathrm{Y}$ capsular polysaccharides, are known to cause the majority of invasive meningococcal disease globally $[1,9,10]$.

The majority of meningitis cases in India are attributed to serogroup A [11-15], with sporadic cases related to serogroup B and C [13]. In India, $N$. meningitidis is the third most common cause of bacterial meningitis in children $<5$ years of age and is responsible for $1.9 \%$ of all cases regardless of age [13]. However, meningococcal disease surveillance in India is not routine, and data on endemic disease are lacking because of insufficient disease surveillance systems and limited availability of diagnostic facilities. It is to be noted that the Integrated Disease Surveillance Program (IDSP) does conduct routine disease surveillance, but this information is not part of the public domain; thus, the actual data on disease surveillance remain unknown. According to a recent review, occasional outbreaks have often been reported in India. These outbreaks may be large in magnitude as reported in Delhi between 2002 and 2004, where 971 confirmed cases were reported [16]. Regardless of outbreak or non-outbreak settings, adolescents and young adults can predominantly be affected [15]. A higher incidence of meningococcal disease has been reported from the temperate northern regions of the country as opposed to tropical southern India, but incidence estimates are not reliable due to suboptimal surveillance and insufficient microbiologic diagnostic support [15]. Together these factors may lead to under-reporting and under-representation of the true meningococcal disease burden in India.

In India, due to the lack of surveillance systems, poor reporting and ease of access to the healthcare system, meningococcal disease incidence is perceived to be low, and meningococcal vaccines are not routinely recommended $[15,17]$. It is therefore likely that the real epidemiology and burden of disease could be underestimated. Available meningococcal vaccines include polysaccharide vaccines and polysaccharide-protein conjugate vaccines against serogroups A, C, W and Y [18]. Serogroup B vaccines are protein-based [18].

This comprehensive narrative review was undertaken to collate and summarize published information on the epidemiology, disease 
burden and challenges in estimating the true burden of meningococcal disease in India. We also report broader vaccination recommendations for the prevention of meningococcal disease beyond outbreak settings and high-risk groups by summarizing data gathered from studies conducted in epidemic and endemic settings.

Figure 1 elaborates on the findings in a form that could be shared with patients by healthcare professionals.

\section{METHODS}

The literature search for this narrative review was conducted according to the Preferred Reporting Items for Systematic Literature Reviews and Meta-Analyses (PRISMA) guidelines [19] to obtain relevant information using a reproducible, robust and transparent methodology. In line with these guidelines, we developed a search strategy and defined eligibility criteria prior to conducting the review. Searches were performed and retrieved publications were assessed for eligibility by two independent reviewers in a two-phase screening process based on the pre-defined eligibility criteria. Data were extracted from the final list of publications that were considered relevant for this review, the scope of data extraction was established a priori.

\section{Search Sources and Strategy}

We searched the Medline (via PubMed) and Embase databases to identify peer-reviewed publications on meningococcal disease in India. The search strategy included both free-text and Emtree/MeSH terms such as "meningococcal infections," "meningococcus," "N. meningitidis" and "India" combined with Boolean operators (Table S1). National and regional World Health Organization (WHO) websites were also searched for information on vaccination recommendations; these searches were not systematically conducted.

\section{Article Eligibility and Screening}

Publications on meningococcal disease in India were considered eligible for inclusion based on the criteria provided in Table 1 . The screening process was limited to articles reported during the last 25 years (1994-2019). Eligible publications were based on: studies on meningococcal disease that focused on the disease burden and epidemiologic outcomes from observational studies, surveillance studies and case reports in India. Reference lists of reviews were consulted to identify additional original studies that may not have been captured by the search in Medline and Embase. Letters to the Editor were included if they contained original data on the disease burden and epidemiology of meningococcal disease in India.

The publications retrieved from databases were screened by two independent researchers based on the eligibility criteria in two phases. The first phase included screening of titles and abstracts. The second phase consisted of reviewing the full-text publications. Any discrepancies in article inclusion were resolved through a discussion between the researchers.

\section{Data Collection and Reporting}

Data extracted from the eligible publications included contextual details (year, study design, geographic region etc.), information on the epidemiology of meningitis (incidence [no. of cases, age-specific estimates, serogroups]), morbidity (carriage, clinical presentation and sequelae) and mortality. Incidence rates are based on suspected cases as defined in the individual studies. Age groups such as neonate (0-30 days of age), pediatric ( 1 month-12 years of age), adolescent (12-18 years of age) and adult ( $>18$ years of age) were defined according to the WHO pediatric age categories [20]. We defined meningococcal meningitis according to the International Classification of Diseases, Tenth Revision, Clinical Modification (ICD-10$\mathrm{CM}$ ): a fulminant infection of the meninges and subarachnoid fluid by the bacterium Neisseria meningitidis, producing diffuse inflammation and peri-meningeal venous thromboses [21]. 
Table 1 Inclusion and exclusion criteria

\begin{tabular}{|c|c|c|}
\hline & Inclusion criteria & Exclusion criteria \\
\hline \multirow[t]{2}{*}{ Population } & All ages ${ }^{\mathrm{a}}$ & \multirow[t]{2}{*}{ Any other } \\
\hline & Meningococcal disease caused by Neisseria meningitidis & \\
\hline Intervention & All interventions & None \\
\hline \multirow[t]{7}{*}{ Outcome } & Incidence & \multirow{7}{*}{$\begin{array}{l}\text { Outcomes other than those covering } \\
\text { epidemiology and burden of disease }\end{array}$} \\
\hline & Number of cases & \\
\hline & Age-specific estimates & \\
\hline & Mortality & \\
\hline & Morbidity & \\
\hline & Clinical presentation & \\
\hline & Carriage & \\
\hline \multirow[t]{7}{*}{ Study design } & Observational studies (retrospective and prospective) & Pre-clinical and clinical studies \\
\hline & Surveillance studies (active, passive) & Meta-analysis \\
\hline & Case-control cohort studies & Letters to the Editor ${ }^{b}$ \\
\hline & \multirow[t]{4}{*}{ Case reports } & Editorial \\
\hline & & Commentary $^{\mathrm{b}}$ \\
\hline & & Opinion paper \\
\hline & & Reviews $^{c}$ \\
\hline Time limit & 25 years (January $1994-S e p t e m b e r ~ 2019)$ & Any other \\
\hline Language & English & Any other language \\
\hline Geographic scope & India & Areas/countries other than in scope \\
\hline
\end{tabular}

a Age group definitions are based on a position paper from the World Health Organization [20]

b Letters to the Editor and commentaries were included if they contained data that were not captured in other eligible publications retrieved from Medline and Embase

c Reference lists of reviews were screened to identify publications of original studies that may not have been captured by the search in Medline and Embase

While there is no ICD definition for meningococcal septicemia, sepsis was defined as lifethreatening organ dysfunction caused by a dysregulated host response to infection [22].

In this review, a descriptive overview of the epidemiology and burden of meningococcal disease in India is presented. Data from the individual studies are categorized into epidemic and endemic meningococcal disease settings, and case reports have been presented separately. Information on clinical characteristics is presented in a single section for studies reporting data from epidemic and endemic settings, and information on antibiotic resistance is presented in a similar manner (i.e., single section for both epidemic and endemic data). An overview of challenges in estimating the burden of meningococcal disease and the current status of meningococcal vaccination recommendations in India is presented. 


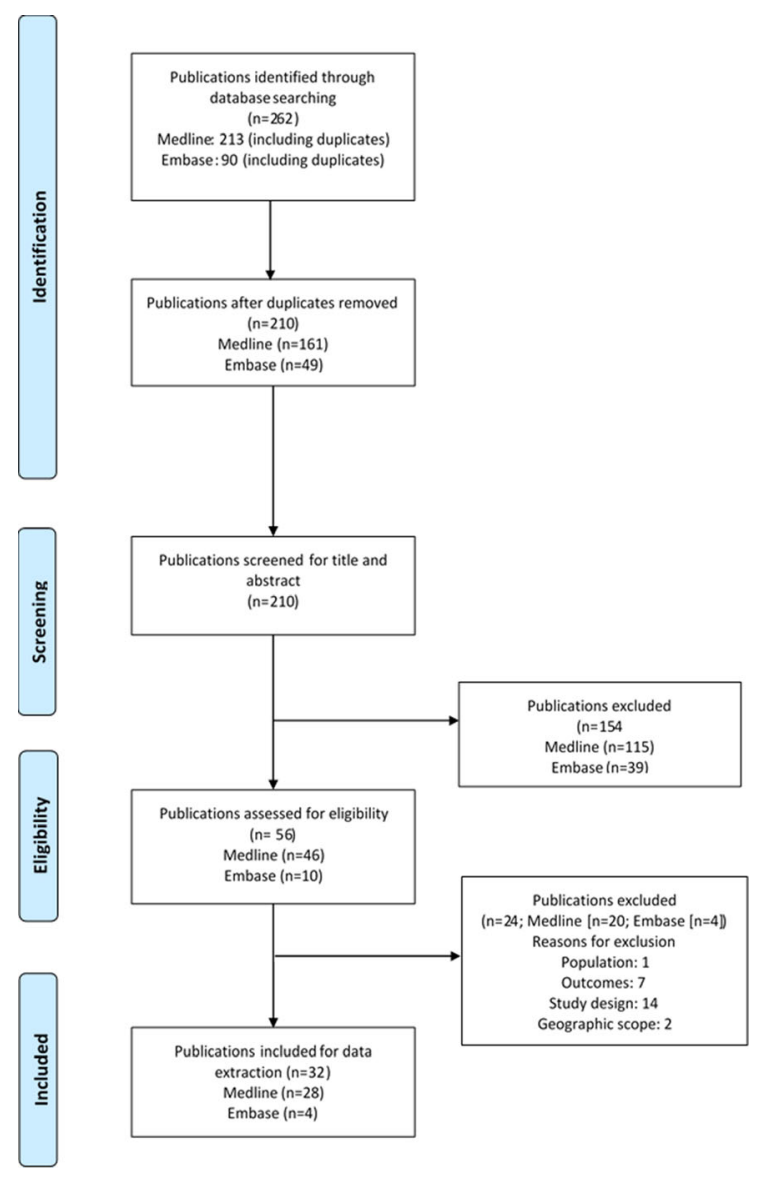

Fig. 2 PRISMA diagram. Template source: The PRISMA Statement [19]

\section{Compliance with Ethics Guidelines}

This article is based on previously conducted studies and does not contain any studies performed by any of the authors with human participants or animals.

\section{RESULTS}

\section{Overview of Included Studies}

A total of 262 publications were identified in the Medline and Embase databases (search cutoff date: August-September 2019). Excluding duplicates, 210 publications were screened based on their titles and abstracts; after excluding ineligible articles, 56 publications were further screened for eligibility based on full-text contents. Finally, 32 publications reporting data from original studies were included in this review [16, 23-53] (Fig. 2).

These 32 publications reported data on meningococcal disease from different regions of India: Delhi $(n=11)[16,24-26,34,40,45-47$, $52,53]$, Karnataka $(n=5)[36,43,44,49,50]$, Assam $(n=3) \quad[28,32,33]$, Kashmir $(n=2)$ $[27,41]$, Chandigarh $(n=2)[37,51]$, Meghalaya $(n=2)[30,31]$, multiple states $(n=2)[38,39]$, Maharashtra $(n=1)$ [29], Uttar Pradesh $(n=1)$ [23], Odisha $(n=1)$ [48], Tripura $(n=1)$ [42] and Tamil Nadu $(n=1)$ [35] (Table 2).

The majority of publications reported data on endemic meningococcal disease $(n=23)$ $[23-25,27-29,31-33,35-38,40,43,44,46$ , 48-53]. Of these 23 publications, 11 were case reports [23-25, 31, 33, 37, 44, 46, 48, 52, 53]. Lastly, 9 publications of the 32 reported data on meningococcal disease in epidemic settings [16, 26, 30, 34, 39, 41, 42, 45, 47] (Table 2).

Excluding the 11 case reports, a total of 20 publications reported disease epidemiology from either retrospective or prospective studies [16, 26-30, 32, 34-36, 38-43, 45, 47, 49, 51]. The study design was not reported for one publication [50] (Table 2).

An equal number of publications reported data for the pediatric population $(n=11)$ $[23,25,29,35,38,46,48-52]$ and mixed populations of different age groups including neonatal, pediatric, adolescent and adult, respectively $[16,28,30,34,36,39,40,42$, $43,45,47]$. A few publications reported data specifically for adult $(n=5)$ [26, 27, 41, 44, 53], adolescent $(n=3)[24,31,37]$ and neonatal $(n=2) \quad[32,33]$ populations, respectively (Table 2).

\section{Epidemic Meningococcal Disease in India}

\section{Overall Incidence and Mortality}

In this review, we identified nine publications that reported incidence and mortality data in outbreak settings in India since 2002 $[16,26,30,34,39,41,42,45,47]$. Seven of these nine publications provided the proportion of confirmed cases of $N$. meningitidis $[26,30,34$, $39,41,42,45,47]$ (Table 2). Of suspected cases, 


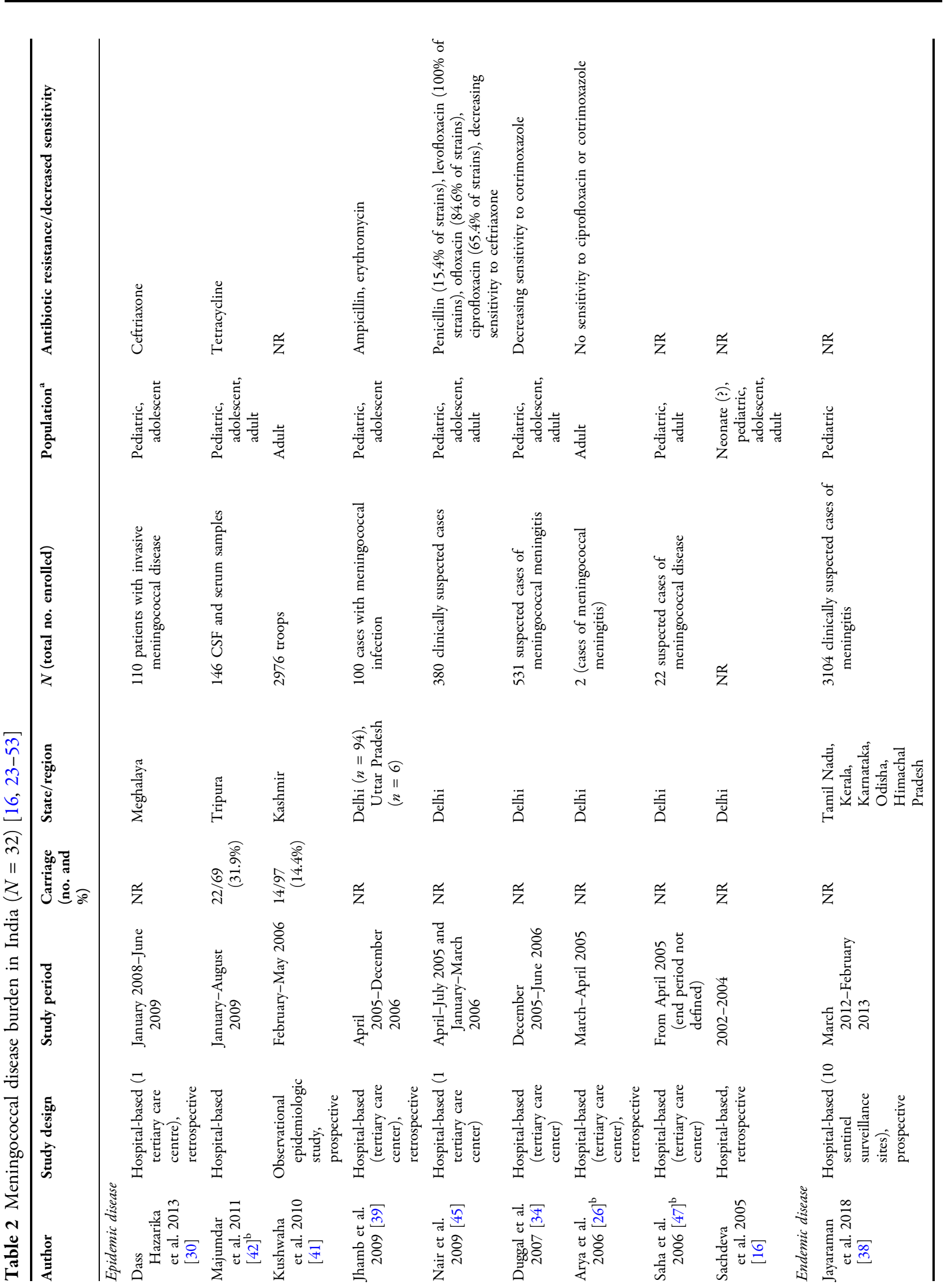




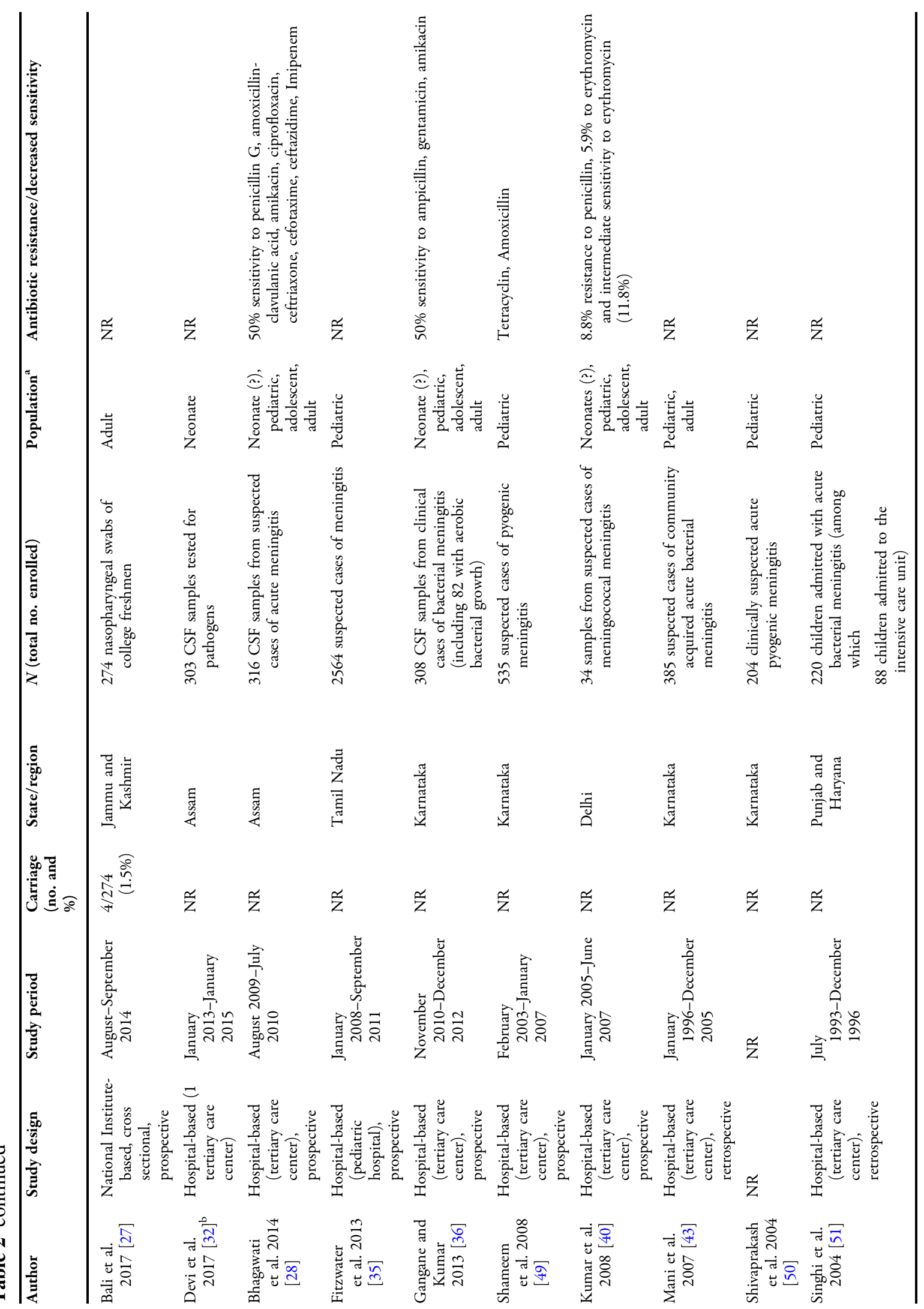




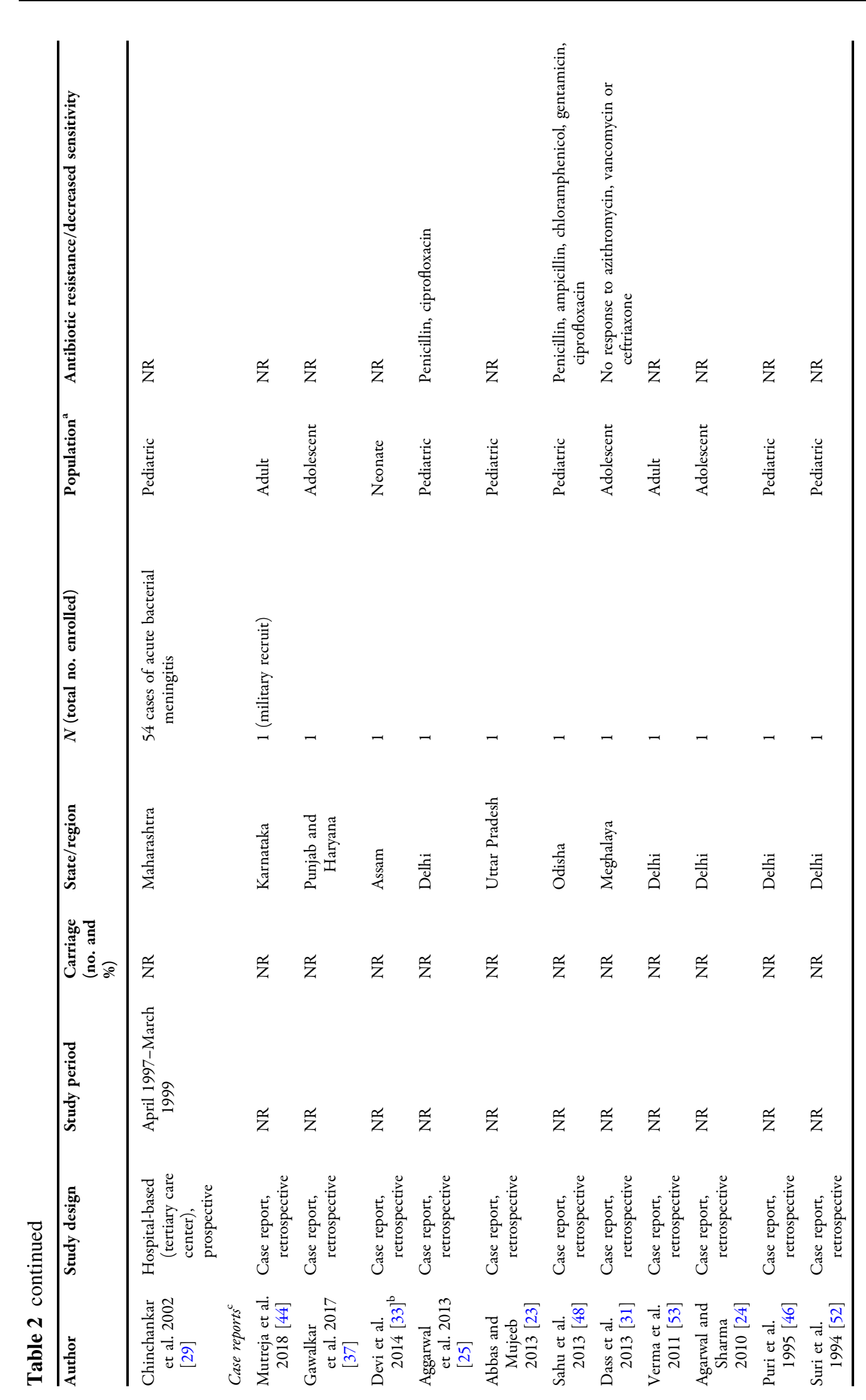




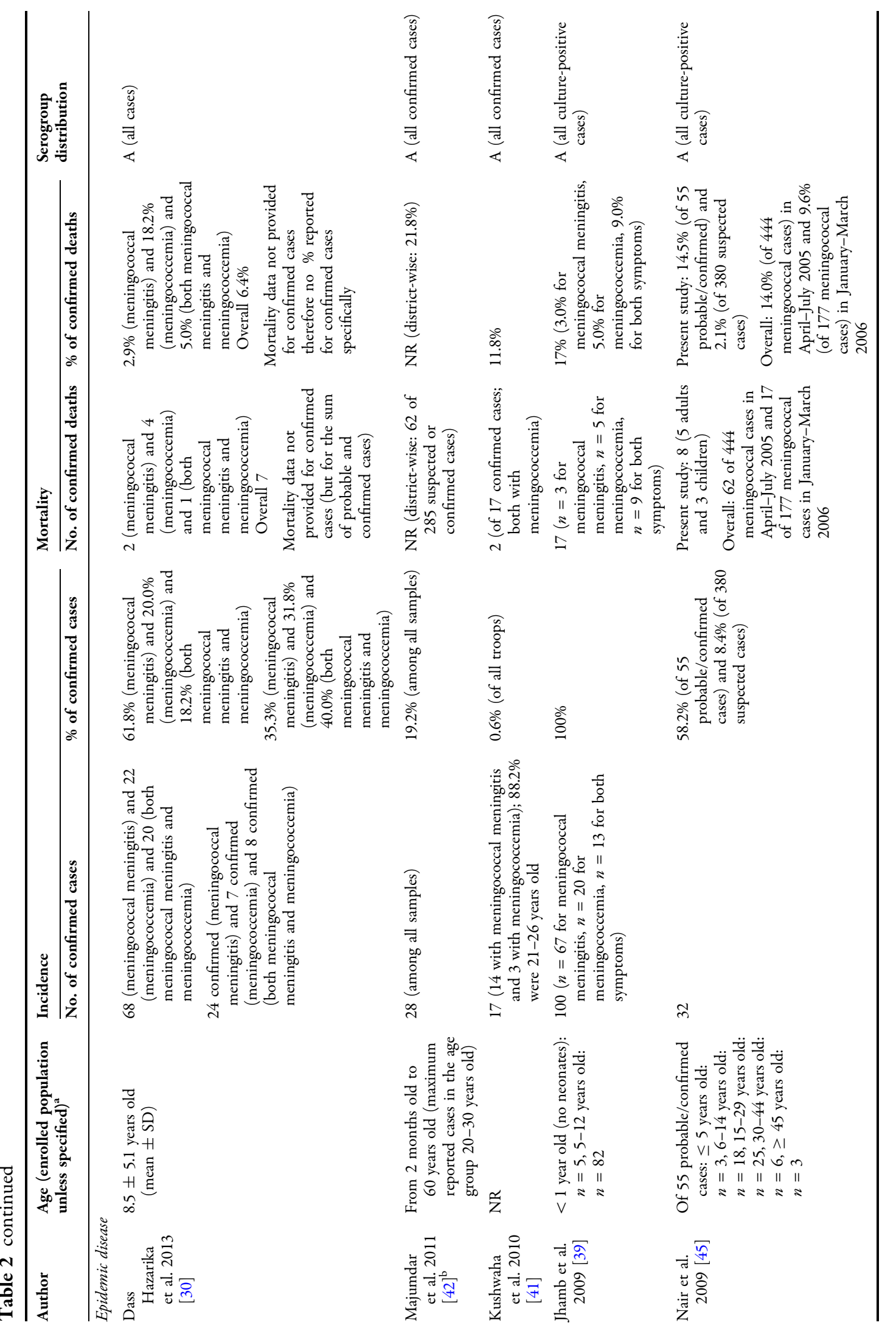




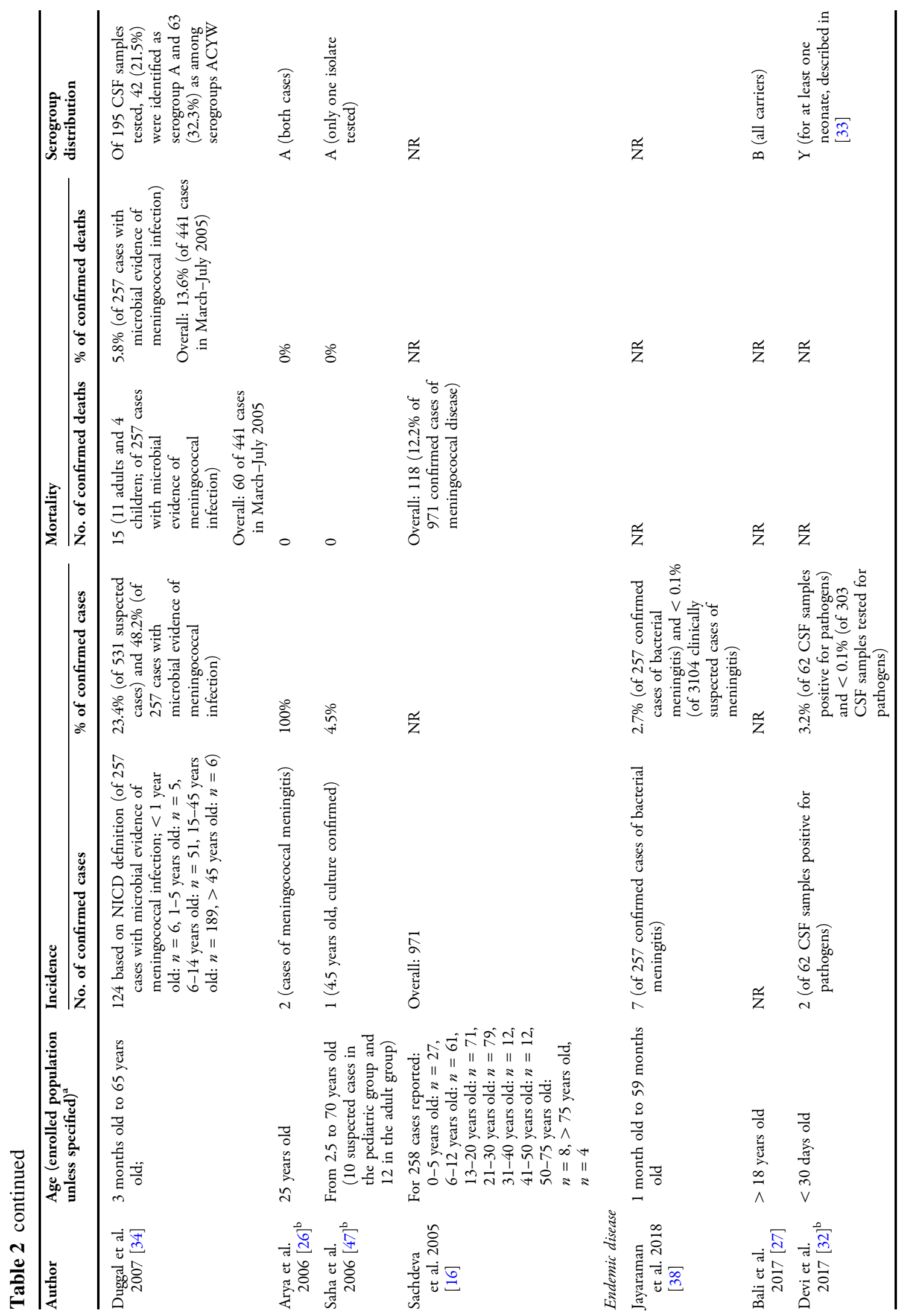




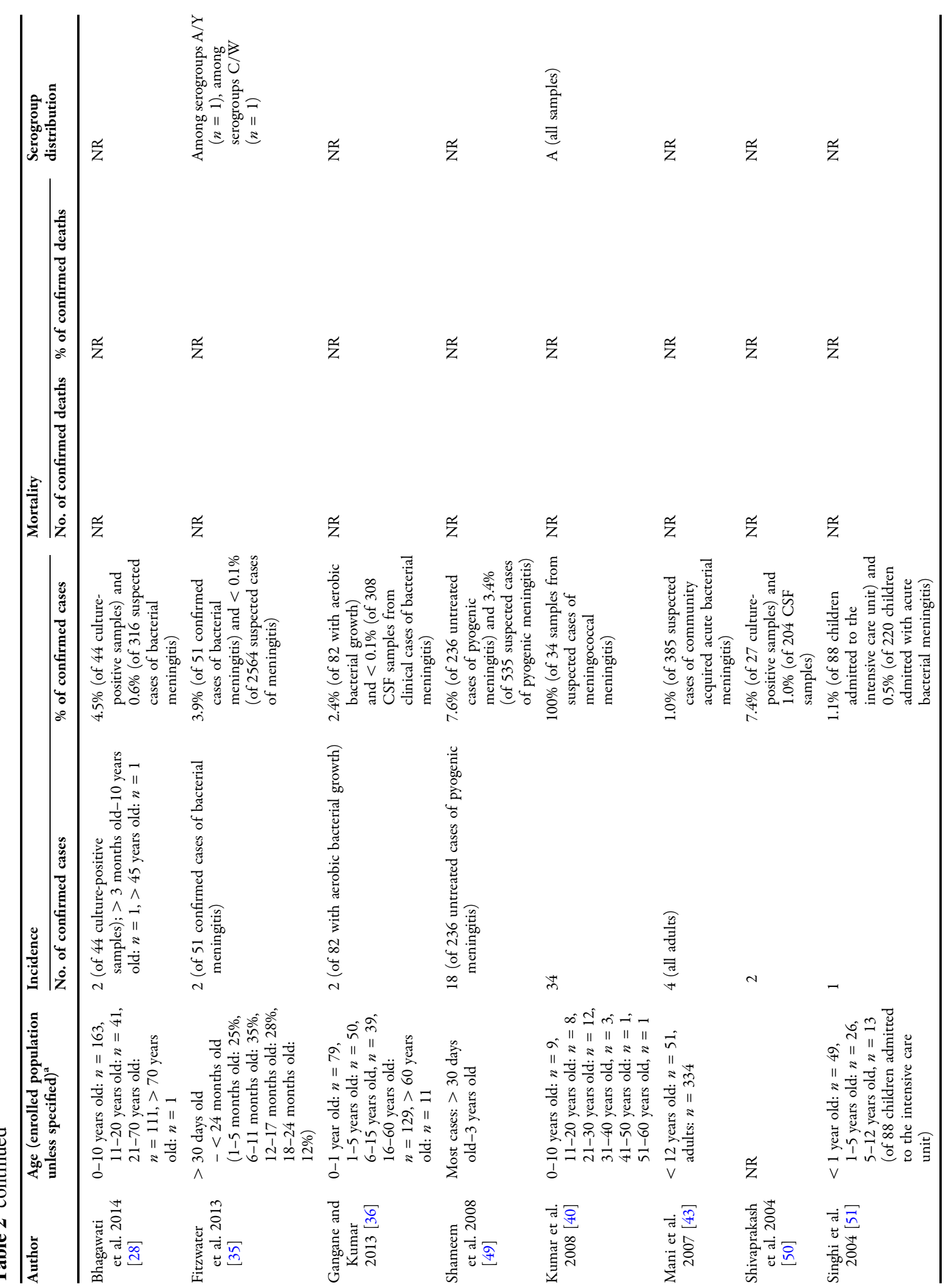




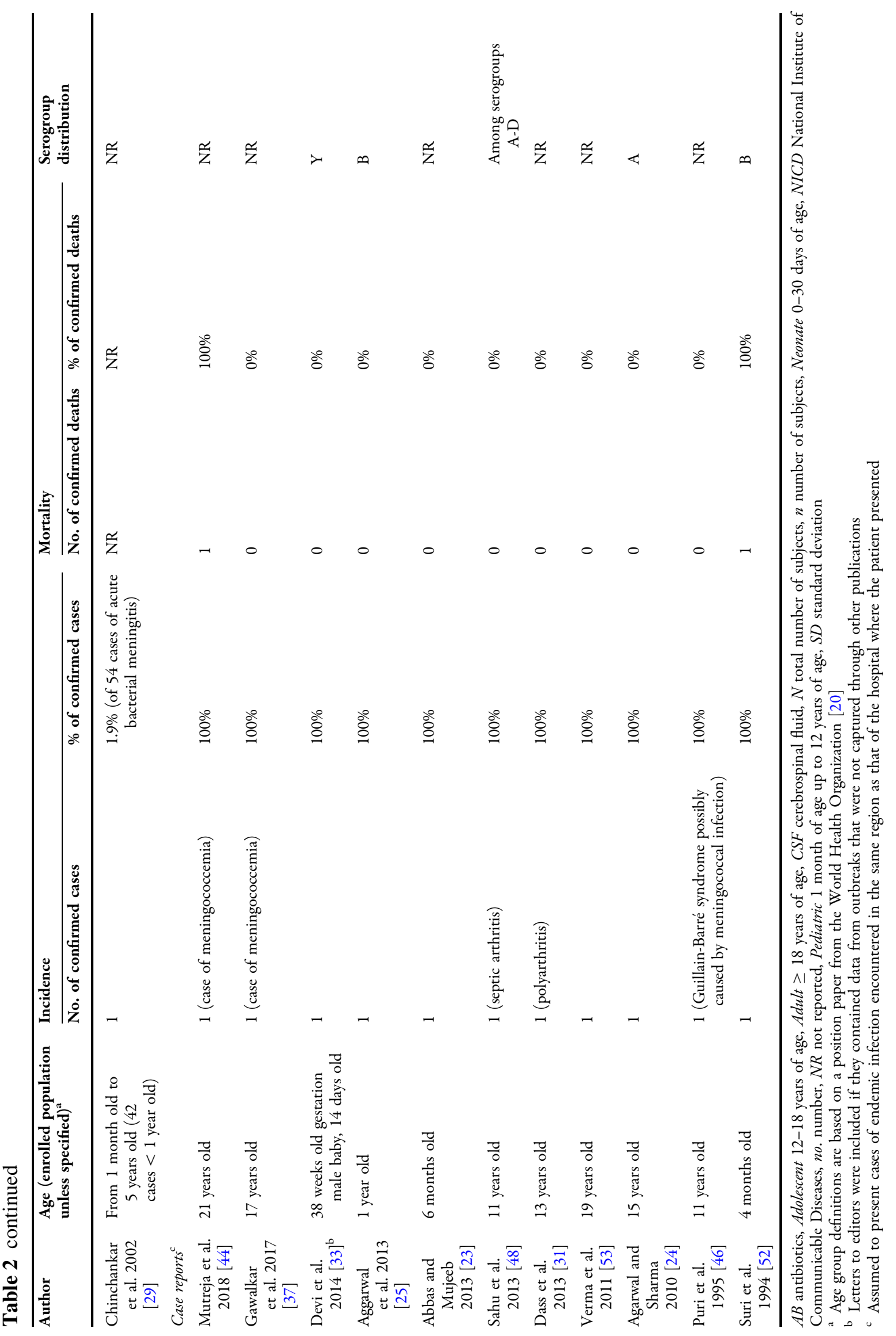


confirmed $N$. meningitidis infection concerned 4.5-23.4\% [34, 42, 45, 47].

The mortality rate due to $N$. meningitidis was reported in nine publications $(0.0-21.8 \%$ of confirmed cases) $[16,26,30,34,39,41,42$, $45,47]$. No deaths were reported in two studies $[26,47]$ (Table 2).

\section{Age- and Serogroup-Specific Distribution}

The age-specific disease burden of $N$. meningitidis cases in outbreak settings was reported in eight publications and included age groups $<2$ months of age to $>75$ years of age $[16,26,30,34,39,42,45,47]$. Notably, an increase was reported in the number of cases among adolescents and adults, which may indicate a shift in the mean age of cases during outbreaks [16, 26, 34, 39, 42, 45] (Table 2).

Serogroup-specific disease burden was reported in eight publications $[26,30,34,39,41,42,45,47]$. The majority of these publications reported the prevalence of serogroup A-specific disease $(n=7)$ $[26,30,39,41,42,45,47]$. In one publication, of the cerebrospinal fluid samples tested, roughly $20 \%$ were positive for serogroup A and $30 \%$ for serogroups A, C, W and Y (specific serogroup was not reported in the study) [34] (Table 2).

\section{Endemic Meningococcal Disease in India}

\section{Overall Incidence and Mortality}

Twelve publications presented data from nonoutbreak settings in India, which reported cases mostly from regions that did not usually have outbreaks. Most publications reported percentages of confirmed cases in the range of 0.1 $(n=2)-7.6 \%$

$(n=18)$

$[28,29,32,35,36,38,43,49-51]$ of suspected cases, and in one publication from Delhi, $71.4-100 \%(n=34)$ of the samples were positive for N.meningitidis, depending on the technique used for diagnosis [40]. Mortality was not reported in any of these publications (Table 2).

\section{Age- and Serogroup-Specific Distribution}

Eight publications provided information on the age-specific distribution of endemic cases
$[28,29,35,36,40,43,49,51]$. Three of those eight publications, having enrolled pediatric, adolescent and adult populations, show that adults and adolescents can represent half or more of the cases of meningococcal disease $[28,40,43]$ (Table 2). Four publications presented specific serogroup information in nonoutbreak settings where serogroups A, B, A/Y (specific serogroup was not reported in the study), C/W (specific serogroup was not reported in the study) and $\mathrm{Y}$ were reported [27, 32, 35, 40] (Table 2).

\section{Clinical Characteristics}

As shown in Table S2, a broad spectrum of clinical presentations associated with N. meningitidis was reported in studies from outbreak settings in India [16, 26, 30, 34, 39, 41, 42, 45]. The preponderant clinical features of meningococcal disease are fever, headache, neck stiffness, vomiting, altered sensorium and bulging anterior fontanelle (specifically in infants). Complications such as raised intracranial pressure, coagulopathy, hepatopathy, arthritis and gangrene have also been reported. Purpura fulminans is present in cases of meningococcemia [26, 30, 34, 39, 41, 42, 45]. Two publications from outbreak settings reported that overcrowding was a risk factor for the carriage and transmission of $N$. meningitidis $[16,41]$.

Clinical presentations of suspected meningitis in non-outbreak settings included fever, headache, neck stiffness, vomiting, altered sensorium and bulging anterior fontanelle (specifically in infants) $[28,29,32,35,38,51]$. We identified one publication with information on serogroup B carriage in a non-outbreak setting [27]. In this single-center study, nasal carriage of $N$. meningitidis (serogroup B) was found in about $1.5 \%$ of the new college hostel residents [27]. Close proximity among the hostellers was reported as the likely risk factor in disease transmission [27] (Table S2).

\section{Antibiotic Sensitivity and Resistance}

Six publications [26, 30, 34, 39, 42, 45] describing studies in epidemic settings and four surveillance studies in endemic settings 
provided information on antibiotic sensitivity and resistance $[28,36,40,49]$. The majority of these studies show sensitivity to penicillin, ampicillin, ceftriaxone, cefotaxime, erythromycin, azithromycin and chloramphenicol.

In one study, resistance to quinolones was considered high for levofloxacin, ofloxacin and ciprofloxacin. MIC90 (minimum inhibitory concentration to inhibit the growth of $90 \%$ of organisms) for ciprofloxacin and levofloxacin was $0.19 \mathrm{mg} / \mathrm{ml}$ and ofloxacin $0.5 \mathrm{mg} / \mathrm{ml}$, all in the resistant range [45]. Resistance/intermediate sensitivity to ciprofloxacin was also found in two other studies [26, 42]. Some isolates with penicillin resistance/intermediate sensitivity were found in one study. In this publication, all patients with penicillin-resistant organisms or intermediate sensitivity succumbed to the disease [45]. In another study good clinical response to ceftriaxone was found in the beginning of the outbreak but increasingly poor response to it after 6 months [30]. One publication also reported reduced sensitivity to cotrimoxazole [34]. Jhamb et al. reported that the majority of isolates were sensitive to penicillin/ ampicillin, ceftriaxone, chloromycetin, ciprofloxacin and erythromycin; only one isolate each was resistant to ampicillin and erythromycin [39].

Similar results of decreased antibiotic sensitivity were reported in four surveillance studies in endemic settings for amoxicillin, ampicillin, erythromycin and penicillins [28, 36, 40, 49].

\section{Case Reports}

\section{Overview of Case Reports}

A total of 11 case reports were included in this review, and all of these presumably reported clinical findings from non-outbreak settings [23-25, 31, 33, 37, 44, 46, 48, 52, 53]. Case reports from Delhi $(n=5)$ [24, 25, 46, 52, 53], Karnataka $(n=1)$ [44], Punjab and Haryana $(n=1)$ [37], Assam $(n=1)$ [33], Uttar Pradesh $(n=1)$ [23], Odisha $(n=1)$ [48] and Meghalaya $(n=1)$ [31] were reported.

\section{Age- and Serogroup-Specific Distribution}

Case reports covered the pediatric $(n=5)$ $[23,25,46,48,52]$, adolescent $(n=3)$ $[24,31,37]$, adult $(n=2)[44,53]$ and neonatal $(n=1)$ [33] populations with ages ranging between 14 days and 21 years (Table 2 ).

Serogroup data were documented in five case reports [24, 25, 33, 48, 52] among which serogroup A, A-D (specific serogroup was not reported in the study) $(n=2)[24,48]$ and the less common serogroups $\mathrm{B}$ and $\mathrm{Y} \quad(n=3)$ $[25,33,52]$ were reported.

\section{Clinical Characteristics}

As shown in Table S2, clinical presentations included symptoms such as fever, headache, neck stiffness, purpuric rash and rarer symptoms perhaps reflecting complex immune reactions, such as joint pains, myocarditis, wheeze and crepitation in the left lower chest $[31,37,44,48,53]$. However, it is not uncommon that meningococci are isolated (culture) from such sites [54, 55].

In another case report, Guillain-Barré syndrome following meningococcal infection was reported, but a causal relationship with the meningococcal infection is not clear [46]. Complications included auto-amputation of toes and fingers and hypotonia [23-25, 46].

\section{Antibiotic Sensitivity and Resistance}

Antibiotic resistance was reported in two case reports for ampicillin, chloramphenicol, ciprofloxacin, gentamicin and penicillin $[25,48]$ (Table 2).

\section{Challenges in Estimating Meningococcal Disease Burden}

Meningococcal disease appears to be a notifiable disease in India, even though reporting is not mandatory $[15,56,57]$. Therefore, challenges in estimating the true burden of meningococcal disease are compounded. Detection of disease using gold standard bacterial culture methods for meningococcal diagnosis are too slow and frequently compromised by prior antibiotic treatment. In India, the widespread availability of antibiotics and 
initiation of treatment prior to sample collection are known to contribute to the increasing number of negative cultures, which impede case detection and confirmation [56]. While other techniques are used, quality control is generally lacking-different methods are used with varying specificities and sensitivities for $N$. meningitidis.

A previous review from India suggests that the meningococcal disease burden in India is not reliably known because of suboptimal surveillance and a poor level of support for microbiologic diagnosis $[15,56]$. We found 23 publications reporting endemic meningococcal disease, 11 of which were case reports presumably not linked to outbreaks, suggesting that endemic meningococcal disease could indeed be severely under-reported and therefore underrecognized [23-25, 27-29, 31-33, 35-38, 40, 43, 44, 46, 48-53].

\section{Recommendations on Meningococcal Vaccination}

According to the WHO, countries with high (> 10 cases/100,000 population/year) or moderate endemic rates (2-10 cases/100,000 population/year) of meningococcal disease and countries with frequent outbreaks should introduce large scale meningococcal vaccination programs. The vaccine may be administered through National Immunization Programs while supplementary immunization activities may be conducted during epidemics. Depending on the national epidemiology and availability of healthcare resources, countries should implement the most appropriate control policy. In countries where the disease occurs less frequently $(<2$ cases/100,000 population/year), the WHO recommends meningococcal vaccination for high-risk groups, such as children and young adults residing in closed communities, e.g., boarding schools or military camps. Laboratory workers at risk of exposure to meningococci and travelers to high-endemic areas should also be vaccinated. According to the WHO, meningococcal vaccination should also be offered to all individuals suffering from immunodeficiencies [18].
Not many countries-but a growing number-have included vaccination against meningococcal disease (such as the quadrivalent MenACWY vaccine; Table 3) in their immunization programs. Countries adapt their vaccination recommendations based on local information about epidemiology, risk groups, disease burden, cost-effectiveness and vaccine impact studies but these data are lacking in most countries. In India, meningococcal vaccination with MenACWY is recommended only for certain high-risk groups of children, during outbreaks and for international travelers, including students going abroad to pursue studies and travelers to the Hajj and sub-Saharan Africa regions [17, 58]. There are no recommendations for meningococcal B vaccination for high-risk groups such as travelers.

\section{DISCUSSION}

We conducted a comprehensive review of the literature to provide an overview of the epidemiology and burden of meningococcal disease in India. The findings from the 32 eligible publications are in line with observations from previous reviews conducted with the same geographic scope of India [13, 15]. Regardless of age or study design, $N$. meningitidis is found in $4.5-23.4 \%[34,42,45,47]$ and $0.1-7.6 \%$ $[28,29,32,35,36,38,43,49-51]$ of suspected meningitis cases in outbreak and non-outbreak settings, respectively. The wide range of disease burden estimates can be explained by differences in study design and setting. In addition, patient age, clinical presentation and confirmation of diagnosis are primary factors that influence estimates of incidence, occurrence of complications and deaths due to meningococcal disease in India. This review reveals that meningococcal disease is not limited only to the pediatric population, but that adolescents and adults are also affected, as previously shown [13]. Adolescents and adults are also known to play a significant role in carriage, especially those living in crowded conditions [27, 41]. Serogroup A disease is identified as the predominant strain during outbreaks in India 
Table 3 National immunization programs/clinical recommendations for routine child-adolescent quadrivalent (A, C, W, Y) meningococcal vaccination from few key countries

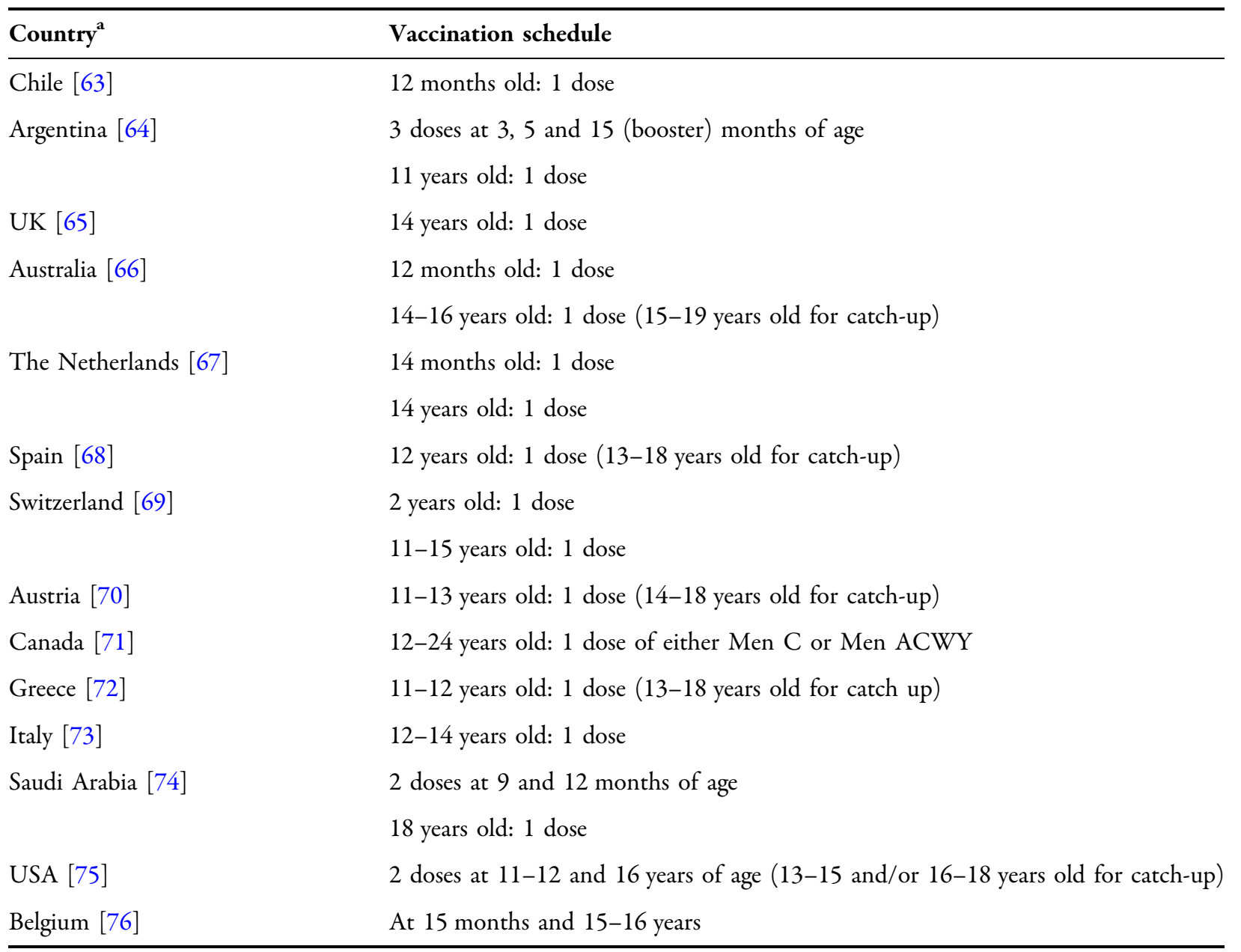

${ }^{a}$ Countries where MenACWY vaccination is in place for specific groups or under specific circumstances (i.e., outbreaks): Czech Republic, Greece, Mauritius, Bahamas, Colombia, Guyana, Panama, Paraguay, Suriname, Trinidad and Tobago, Egypt, Iran, Oman, Qatar, United Arab Emirates, Armenia, Israel, Russian Federation, Serbia, Slovenia, Maldives, Brunei Darussalam, Malaysia, New Zealand [77]

[26, 30, 39, 41, 42, 45, 47], but other serogroups (B, C, Y and $\mathrm{W}$ ) are also documented in endemic settings [25, 27, 32, 33, 35, 52]. These observations are consistent with findings from Asia and the Pacific region, which show that serogroup A disease is most prominent in low-income countries such as the Philippines, while other countries like China, Taiwan, Japan and Korea have documented a mixed epidemiology of serogroups A, B, C and W [14].

In this review, 23 publications from nonoutbreak settings are reported, 11 of which are case reports of individual patients
$[23-25,27-29, \quad 31-33,35-38,40,43,44$, $46,48-53]$. The reporting of the disease burden estimates from non-outbreak settings might therefore be skewed in their presentation of the true disease burden. A previous review states that the burden of endemic meningococcal disease in India is difficult to quantify [56]. Low bacterial detection rates in many studies, considered to be the result of both technical laboratory aspects and high levels of antibiotic use, have prevented the provision of true disease burden estimates in India [56]. 
In the case of meningococcal disease caused by $N$. meningitidis, immediate initiation of parenteral antibiotics, preferably within half an hour after hospital admission or diagnosis, remains the mainstay of treatment. Rapid initiation of antibiotic therapy is known to prevent foreseen complications such as septic shock, raised intracranial pressure and mortality. However, indiscriminate use of antibiotics has led to reduced antibiotic sensitivity and antibiotic-resistant strains of bacteria as reported in several studies in outbreak and non-outbreak settings $[25,26,28,30,31,36,39,40$, $42,45,48,49]$. These disadvantages of using antibiotics suggest that a better approach to reducing the disease burden and tackling high mortality rates due to meningococcal infections is through vaccination $[3,18]$.

Given the perceived low incidence of meningococcal disease, meningococcal vaccination is not routinely administered in India. The Indian Academy of Pediatrics (IAP) recommends meningococcal vaccination only for certain high-risk groups of children such as those with congenital or acquired immunodeficiency, during outbreaks, for international travelers such as students studying abroad and travelers to Hajj and sub-Saharan Africa and for household contacts $[15,17]$. The IAP also recommends conjugate vaccines rather than polysaccharide meningococcal vaccines [17]. This is because polysaccharide vaccines are associated with immunologic shortcomings, such as poor immunogenicity in children < 2 years of age, inability to generate immune memory and provision of only transient and incomplete protection against carriage. For these reasons, polysaccharide vaccines do not substantially contribute to herd immunity and induce hyporesponsiveness [17, 18]. Lastly, vaccines for serogroup B could be beneficial for travelers going to areas with high or intermediate endemicity of meningitis.

Designing the most effective vaccination strategy for a particular country or setting is best guided by robust epidemiologic data, especially to detect outbreaks and to determine the need for vaccination. While the IDSP conducts routine disease surveillance within the country, the corresponding data are not part of the public domain [57]. The available data provided by the National Health Statistics present a high rate of meningococcal disease incidence, which cannot be confirmed independently [59-61]. These findings are in line with the situation analyzed for Asia and the Pacific region, which indicates that meningococcal disease is under-reported in this region [14]. The review of Sinclair et al., specific to India, shows that, despite incomplete reporting, meningococcal meningitis has been a notifiable disease in India over the past decades and that the country is susceptible to outbreaks [13]. As robust epidemiologic data on meningococcal disease in India are lacking, reliable longitudinal surveillance systems are urgently needed to characterize meningococcal disease epidemiology, including a standard clinical case definition, field investigation of cases and outbreaks, and laboratory capacity for the confirmation and characterization of $N$. meningitidis serogroups. In addition, the continued surveillance of meningococcal disease including developing resistance patterns in $N$. meningitidis should dictate the need and timing of repeat mass vaccination campaigns.

\section{LIMITATIONS AND FUTURE RESEARCH}

This narrative review has several limitations related to the methodology such as the exclusion of gray literature sources (i.e., literature not peer-reviewed prior to publication such as government databases and reports) in the systematic search, conducted in Medline and Embase. As we aimed to obtain a better understanding of published epidemiology and disease burden data, broadening our search to other sources and having a risk-of-bias analysis was not deemed necessary.

Generalizability of the results from this review should be done cautiously as incidence rates were presented based on suspected cases as defined by the individual studies and case reports. Furthermore, not all articles provide adequate data regarding methods used for microbiologic diagnosis and serogroup analysis.

Barriers to eliciting the true disease burden of meningococcal disease include factors related to 
a lack of reporting in the individual studies driven by suboptimal surveillance infrastructure and insufficient diagnostic facilities. The application of sensitive quantitative polymerase chain reaction assays [62] can prove useful in epidemiologic studies to improve knowledge of the true burden of meningococcal disease in India. Also, the true estimate of antibiotic resistance is lacking as not all data are available for each publication and as such treatment modalities are not discussed. Research into the use of advanced, more discriminate diagnostics methods, such as multilocus sequence typing and microscopic agglutination test, may provide information on the clonal dispersion of reported cases in India, including antibiotic resistance. However, logistical and financial considerations have to be taken into account to evaluate the feasibility of large-scale implementation of such methods for disease surveillance in India.

\section{CONCLUSION}

Meningococcal disease surveillance in India is not routine and data on endemic disease remain insufficient. Occasional outbreaks of meningococcal disease have been documented in India affecting adolescents and young adults in addition to the pediatric population. The endemic meningococcal disease burden in India is underestimated because of the suboptimal surveillance infrastructure. To this end, the establishment of routine surveillance for bacterial meningitis and standardizing protocols for laboratory diagnosis demand urgent attention.

Despite the availability of safe and effective meningococcal vaccines, routine meningococcal vaccination is not recommended in India. Given the recommendation from the IAP, the use of meningococcal conjugate vaccines could contain future epidemics of meningococcal disease if detected early through improved surveillance. In addition, the routine immunization of high-risk individuals as well as adolescents and adults involved in carriage and transmission of the disease could be beneficial to prevent the occurrence of outbreaks.

\section{ACKNOWLEDGEMENTS}

Funding. GlaxoSmithKline Biologicals SA funded this review and all costs associated with its development and publication. All authors had full access to all of the data in this study and take complete responsibility for the integrity of the data and accuracy of the data analysis.

Authorship. All named authors meet the International Committee of Medical Journal Editors (ICMJE) criteria for authorship for this article, take responsibility for the integrity of the work as a whole, and have given their approval for this version to be published.

Medical Writing, Editorial and Other Assistance. The authors thank Arun Dahiya (previously employed by GSK) for his initial contribution and help with preparation of the manuscript and Ashish Agrawal (employed by GSK) who was involved in the conduct of the review. The authors also thank Business \& Decision Life Sciences platform for editorial assistance and manuscript coordination on behalf of GSK. Benjamin Lemaire provided editorial assistance and coordinated publication development. Amrita Ostawal (Arete Communication UG, Berlin, Germany) provided medical writing assistance. Editorial support and medical writing assistance were funded by GlaxoSmithKline Biologicals SA.

Disclosures. Ashok Kumar Dutta received personal fees, outside the submitted work, from the GSK group of companies, Sanofi Pasteur, Abott Vaccine, Zuventus Health Care and Pfizer vaccine for serving on advisory boards and declares no non-financial conflicts of interest. Subramanian Swaminathan is on the advisory board or a speaker for GSK, Pfizer, Mylan, Astellas, Sanofi, MSD, Baxter, Cipla, Glenmark and ThermoFisher and declares no non-financial conflicts of interest. Veronique Abitbol is an employee of the GSK group of companies, holds shares as part of her employee remuneration and declares no non-financial conflicts of interest. Shafi Kolhapure is an employee of the 
GSK group of companies, holds shares as part of his employee remuneration and declares no non-financial conflicts of interest. Sripriya Sathyanarayanan is an employee of the GSK group of companies and declares no non-financial conflicts of interest.

Compliance with Ethics Guidelines. This article is based on previously conducted studies and does not contain any studies performed by any of the authors with human participants or animals.

Data Availability. Data sharing is not applicable to this article as no datasets were generated or analyzed in the current study.

Open Access. This article is licensed under a Creative Commons Attribution-NonCommercial 4.0 International License, which permits any non-commercial use, sharing, adaptation, distribution and reproduction in any medium or format, as long as you give appropriate credit to the original author(s) and the source, provide a link to the Creative Commons licence, and indicate if changes were made. The images or other third party material in this article are included in the article's Creative Commons licence, unless indicated otherwise in a credit line to the material. If material is not included in the article's Creative Commons licence and your intended use is not permitted by statutory regulation or exceeds the permitted use, you will need to obtain permission directly from the copyright holder. To view a copy of this licence, visit http:// creativecommons.org/licenses/by-nc/4.0/.

\section{REFERENCES}

1. Rosenstein NE, Perkins BA, Stephens DS, Popovic T, Hughes JM. Meningococcal disease. N Engl J Med. 2001;344(18):1378-88.

2. World Health Organization. Control of epidemic meningococcal disease. WHO practical guidelines. 2nd edition. https://www.who.int/csr/resources/ publications/meningitis/whoemcbac983.pdf?ua $=1$. Accessed 30 Sep 2019.
3. World Health Organization. Meningococcal meningitis. 2018. https://www.who.int/en/newsroom/fact-sheets/detail/meningococcal-meningitis. Accessed 30 Sep 2019.

4. Caugant DA, Hoiby EA, Magnus P, Scheel O, Hoel T, Bjune $\mathrm{G}$, et al. Asymptomatic carriage of Neisseria meningitidis in a randomly sampled population. J Clin Microbiol. 1994;32(2):323-30.

5. Peterson ME, Li Y, Shanks H, Mile R, Nair H, Kyaw $\mathrm{MH}$, et al. Serogroup-specific meningococcal carriage by age group: a systematic review and metaanalysis. BMJ Open. 2019;9(4):e024343.

6. al-Gahtani YM, el Bushra HE, al-Qarawi SM, alZubaidi AA, Fontaine RE. Epidemiological investigation of an outbreak of meningococcal meningitis in Makkah (Mecca), Saudi Arabia, 1992. Epidemiol Infect. 1995; 115(3):399-409.

7. Yezli S, Wilder-Smith A, Bin Saeed AA. Carriage of Neisseria meningitidis in the Hajj and Umrah mass gatherings. Int J Infect Dis. 2016;47:65-70.

8. Caugant DA, Høiby EA, Rosenqvist E, Frøholm LO, Selander RK. Transmission of Neisseria meningitidis among asymptomatic military recruits and antibody analysis. Epidemiol Infect. 1992;109(2): 241-53.

9. Schwartz B, Moore PS, Broome CV. Global epidemiology of meningococcal disease. Clin Microbiol Rev. 1989;2:S118-24.

10. Purmohamad A, Abasi E, Azimi T, Hosseini S, Safari $\mathrm{H}$, Nasiri MJ, et al. Global estimate of Neisseria meningitidis serogroups proportion in invasive meningococcal disease: a systematic review and meta-analysis. Microb Pathog. 2019;134:103571.

11. Manchanda V, Gupta S, Bhalla P. Meningococcal disease: history, epidemiology, pathogenesis, clinical manifestations, diagnosis, antimicrobial susceptibility and prevention. Indian J Med Microbiol. 2006;24(1):7-19.

12. Prakash K, Lakshmy A, Malhotra VL. Neisseria meningitidis: serotyping and subtyping by whole cell ELISA. Br J Biomed Sci. 1993;50(3):174-7.

13. Sinclair D, Preziosi MP, Jacob John T, Greenwood B. The epidemiology of meningococcal disease in India. Trop Med Int Health. 2010;15(12):1421-35.

14. Borrow R, Lee JS, Vazquez JA, Enwere G, Taha MK, Kamiya $\mathrm{H}$, et al. Meningococcal disease in the AsiaPacific region: findings and recommendations from the Global Meningococcal Initiative. Vaccine. 2016;34(48):5855-62. 
15. John TJ, Gupta S, Chitkara AJ, Dutta AK, Borrow R. An overview of meningococcal disease in India: knowledge gaps and potential solutions. Vaccine. 2013;31(25):2731-7.

16. Sachdeva A, Kukreja S, Jain V, Dutta AK. Meningococcal disease-outbreak in Delhi. Indian Pediatr. 2005;42(6):547-56.

17. Vashishtha VM, Choudhury P, Jog P, Yadav S, Unni J, Kamath S, et al. Indian Academy of Pediatrics (IAP) recommended immunization schedule for children aged 0 through 18 years, India, 2014 and updates on immunization. Indian Pediatr. 2014;51(10):785-800.

18. World Health Organization. Meningococcal vaccines: WHO position paper, November 2011. 2011. https://www.who.int/wer/2011/wer8647.pdf. Accessed 01 Oct 2019.

19. Moher D, Liberati A, Tetzlaff J, Altman DG, The PG. Preferred reporting items for systematic reviews and meta-analyses: the PRISMA statement. PLOS Med. 2009;6(7):e1000097.

20. World Health Organization. Position paper: paediatric age categories to be used in differentiating between listing on a model essential medicines list for children. 2007. http://archives.who.int/eml/ expcom/children/Items/PositionPaperAgeGroups. pdf. Accessed 20 Jan 2020.

21. ICD10Data.com. International classification of diseases, tenth revision, clinical modification (ICD-10CM). 2020. https://www.icd10data.com/ICD10CM/ Codes/A00-B99/A30-A49/A39-/A39.0. Accessed 16 Apr 2020.

22. Singer M, Deutschman CS, Seymour CW, ShankarHari M, Annane D, Bauer M, et al. The third international consensus definitions for sepsis and septic shock (sepsis-3). JAMA. 2016;315(8):801-10.

23. Abbas A, Mujeeb AA. Purpura fulminans caused by meningococcemia in an infant. BMJ Case Rep. 2013;2013:bcr2013200265.

24. Agarwal MP, Sharma V. Clinical images: purpura fulminans caused by meningococcemia. CMAJ. 2010;182(1):E18.

25. Aggarwal M, Manchanda V, Talukdar B. Meningitis due to Neisseria meningitidis serogroup B in India. Indian Pediatr. 2013;50(6):601-3.

26. Arya S, Gupta S, Gupta S, Mehta L, Agarwal N, Khare S. Early management of meningococcal disease. Aust Fam Physician. 2006;35(6):376.

27. Bali NK, Mir H, Tantray VG, Ali S, Kakru DK, Koul PA. Meningococcal carriage among college freshmen in Kashmir, North India-a single centre study. J Clin Diagn Res. 2017;11(10):13-7.

28. Bhagawati G, Dipa B, Naba H, Jasmin H, Sharon R. Bacteriological profile of acute meningitis: a one year study in a tertiary care centre in Assam. Indian J Public Health Res Dev. 2014;5(3):210-4.

29. Chinchankar N, Mane M, Bhave S, Bapat S, Bavdekar A, Pandit A, et al. Diagnosis and outcome of acute bacterial meningitis in early childhood. Indian Pediatr. 2002;39(10):914-21.

30. Dass Hazarika R, Deka NM, Khyriem AB, Lyngdoh WV, Barman H, Duwarah SG, et al. Invasive meningococcal infection: analysis of 110 cases from a tertiary care centre in North East India. Indian J Pediatr. 2013;80(5):359-64.

31. Dass R, Barman H, Duwarah SG, Deka NM, Jain P, Choudhury $\mathrm{V}$. Immune complex reaction after successful treatment of meningococcal disease: an excellent response to IVIG. Rheumatol Int. 2013;33(1):231-3.

32. Devi U, Bora R, Malik V, Deori R, Gogoi B, Das JK, et al. Bacterial aetiology of neonatal meningitis: a study from north-east India. Indian J Med Res. 2017;145(1):138-43.

33. Devi U, Mahanta J. Neonatal meningitis due to Neisseria meningitidis serogroup Y. Indian Pediatr. 2014;51(9):757.

34. Duggal S, Duggal N, Charoo H, Mahajan RK. Recent outbreak of meningococcal meningitis-a microbiological study with brief review of literature. J Commun Dis. 2007;39(4):209-16.

35. Fitzwater SP, Ramachandran P, Nedunchelian K, Kahn G, Santosham M, Chandran A. Bacterial meningitis in children $<2$ years of age in a tertiary care hospital in South India: an assessment of clinical and laboratory features. J Pediatr. 2013;163: S32-7.

36. Gangane R, Kumar D. Bacteriological profile of bacterial meningitis at tertiary care hospital in north karnataka. Int J Pharma Bio Sci. 2013;4: B1356-61.

37. Gawalkar AA, Tale S, Chhabria BA, Bhalla A. Myocarditis and purpura fulminans in meningococcaemia. QJM. 2017;110(11):755-6.

38. Jayaraman Y, Veeraraghavan B, Chethrapilly Purushothaman GK, Sukumar B, Kangusamy B, Nair Kapoor A, et al. Burden of bacterial meningitis in India: preliminary data from a hospital based sentinel surveillance network. PLoS One. 2018;13(5): e0197198. 
39. Jhamb U, Chawla V, Khanna S. Clinical profile of group A meningococcal outbreak in Delhi. Indian Pediatr. 2009;46(9):794-6.

40. Kumar S, Kashyap B, Bhalla P. The rise and fall of epidemic Neisseria meningitidis from a tertiary care hospital in Delhi, January 2005-June 2007. Trop Doct. 2008;38(4):222-4.

41. Kushwaha AS, Aggarwal SK, Arora MM. Outbreak of meningococcal infection amongst soldiers deployed in operations. Med J Arm Forces India. 2010;66(1):4-8.

42. Majumdar T, Bhattacharya S, Barman D, Begum R. Laboratory confirmed outbreak of meningococcal infections in Tripura. Indian J Med Microbiol. 2011;29(1):74-6.

43. Mani R, Pradhan S, Nagarathna S, Wasiulla R, Chandramuki A. Bacteriological profile of community acquired acute bacterial meningitis: a ten-year retrospective study in a tertiary neurocare centre in South India. Indian J Med Microbiol. 2007;25(2): 108-14.

44. Mutreja D, Moorchung N, Manasa SJ, Varghese J. Fatal meningococcal septicemia without meningeal signs, contribution of the peripheral smear in diagnosis: report of a case. Indian J Pathol Microbiol. 2018;61(2):284-6.

45. Nair D, Dawar R, Deb M, Capoor MR, Singal S, Upadhayay DJ, et al. Outbreak of meningococcal disease in and around New Delhi, India, 2005-2006: a report from a tertiary care hospital. Epidemiol Infect. 2009;137(4):570-6.

46. Puri V, Khalil A, Suri V. Guillain-Barre syndrome following meningococcal meningitis. Postgrad Med J. 1995;71(831):42-3.

47. Saha R, Gadre D, Mathur M. Meningococcaemia: experience at a tertiary care hospital in East Delhi. Indian J Med Microbiol. 2006;24(4):299-300.

48. Sahu S, Mohanty I, Narasimham MV, Pasupalak S, Parida B. Primary meningococcal arthritis of sacroiliac joint: a rare case report. Indian J Med Microbiol. 2013;31(1):87-9.

49. Shameem S, Vinod Kumar CS, Neelagund YF. Bacterial meningitis: rapid diagnosis and microbial profile: a multicentered study. J Commun Dis. 2008;40(2):111-20.

50. Shivaprakash MR, Rajagopal V, Nagarathna S. Latex agglutination test in the diagnosis of pyogenic meningitis. J Commun Dis. 2004;36(2):127-31.

51. Singhi SC, Khetarpal R, Baranwal AK, Singhi PD. Intensive care needs of children with acute bacterial meningitis: a developing country perspective. Ann Trop Paediatr. 2004;24(2):133-40.

52. Suri M, Kabra M, Singh S, Rattan A, Verma IC. Group B meningococcal meningitis in India. Scand J Infect Dis. 1994;26(6):771-3.

53. Verma N, Verma R, Sood S, Das BK, Singh P, Kumar A, et al. Primary meningococcal polyarthritis in a young man. Natl Med J India. 2011;24(5):278-9.

54. Winstead JM, McKinsey DS, Tasker S, De Groote MA, Baddour LM. Meningococcal pneumonia: characterization and review of cases seen over the past 25 years. Clin Infect Dis. 2000;30(1):87-94.

55. Masson-Behar V, Jacquier H, Richette P, Ziza JM, Zeller V, Rioux C, et al. Arthritis secondary to meningococcal disease: a case series of 7 patients. Medicine. 2017;96(29):e7573.

56. Vyse A, Wolter JM, Chen J, Ng T, Soriano-Gabarro $\mathrm{M}$. Meningococcal disease in Asia: an under-recognized public health burden. Epidemiol Infect. 2011;139(7):967-85.

57. Ministry of Health and Family Welfare GoI. Integrated disease surveillance program (IDSP). Diseases under surveillance. 2020. https://idsp.nic.in/ index1.php?lang=1\&level $=1 \&$ sublinkid $=5985 \&$ lid= 3925. Accessed 16 Apr 2020.

58. Balasubramanian S, Shah A, Pemde HK, Chatterjee $P$, Shivananda S, Guduru VK, et al. Indian Academy of Pediatrics (IAP) Advisory Committee on vaccines and immunization practices (ACVIP) recommended immunization schedule (2018-19) and update on immunization for children aged 0 through 18 years. Indian Pediatr. 2018;55(12):1066-74.

59. Central Bureau of Health Intelligence. About Central Bureau of Health Intelligence. 2016. https:// cbhidghs.nic.in/. Accessed 16 Apr 2020.

60. Central Bureau of Health Intelligence. Meningococcal meningitis. 2016. https://www.slideshare. net/silchar14/meningococcal-meningitis65272017. Accessed 16 Apr 2020.

61. Central Bureau of Health Intelligence. National Health Profile 2018. 2018. http://www.cbhidghs. nic.in/Ebook/National\%20Health\%20Profile-2018 \%20(e-Book)/files/assets/common/downloads/files/ NHP\%202018.pdf. Accessed 16 Apr 2020.

62. Moore JE. Meningococcal disease section 3: diagnosis and management: meningoNI forum. Ulster Med J. 2018;87(2):94-8.

63. Ministerio de Salud (Chile). Programa Nacional de Inmunizaciones 2020. https://www.minsal.cl/ 
programa-nacional-de-inmunizaciones. Accessed 16 Apr 2020.

64. Ministerio de Salud (Argentina). Calendario nacional de vacunacion 2019. http://www.msal.gob.ar/ images/stories/ryc/graficos/0000001386cnt-2019_ calendario-nacional-vacunacion.jpg. Accessed 16 Apr 2020.

65. National Health Service (United Kingdom). Routine childhood immunisations 2020. https://assets. publishing.service.gov.uk/government/uploads/ system/uploads/attachment_data/file/849165/PHE_ childhood_immunisation_schedule_Jan2020.pdf. Accessed 16 Apr 2020.

66. Australian Capital Territory Government| Health. Immunisation Services 2020. https://www.health. act.gov.au/services/immunisation. Accessed $16 \mathrm{Apr}$ 2020 .

67. National Institute for Public Health and the Environment. Which vaccines will my child receive? https://rijksvaccinatieprogramma.nl/sites/default/ files/2019-12/RVP\%20infographic\% 20vaccinatieschema\%20EN\%202020.pdf. Accessed 16 Apr 2020.

68. Ministerio de Sanidad, Consumo y Bienestar Social. Preguntas y respuestas sobre la vacunacion frente a la meningitis. https://www.mscbs.gob.es/profes ionales/saludPublica/prevPromocion/vacunaciones /docs/Preguntas_respuestas_Vacunacion_frente_me ningitis.pdf. Accessed 16 Apr 2020.

69. Office fédéral de la Santé Publique (Switzerland). Plan de vaccination suisse 2019. https://www. infovac.ch/docs/public/fs/plan-de-vaccination2019.pdf. Accessed 16 Apr 2020.

70. European Centre for Disease Prevention and Control. Meningococcal Disease: Recommended vaccinations (Austria). https://vaccine-schedule.ecdc. europa.eu/Scheduler/ByDisease?SelectedDiseaseId= 48\&SelectedCountryIdByDisease $=18$. Accessed 16 Apr 2020.

71. Government of Canada|Public Health Services. Meningococcal vaccine: Canadian Immunization
Guide 2020. https://www.canada.ca/en/publichealth/services/publications/healthy-living/canadia n-immunization-guide-part-4-active-vaccines/page13-meningococcal-vaccine.html\#routine. Accessed 16 Apr 2020.

72. European Centre for Disease Prevention and Control. Meningococcal Disease: Recommended vaccinations (Greece). https://vaccine-schedule.ecdc. europa.eu/Scheduler/ByDisease?SelectedDiseaseId= $48 \&$ SelectedCountryIdByDisease $=82$. Accessed 16 Apr 2020.

73. European Centre for Disease Prevention and Control. Meningococcal Disease: Recommended vaccinations (Italy). https://vaccine-schedule.ecdc. europa.eu/Scheduler/ByDisease?SelectedDiseaseId= $48 \&$ SelectedCountryIdByDisease $=103$. Accessed 16 Apr 2020.

74. Ministry of Health Saudi Arabia. National immunization schedule. https://www.moh.gov.sa/en/ HealthAwareness/EducationalContent/HealthTips/ Documents/Immunization-Schedule.pdf. Accessed 16 Apr 2020.

75. Centers for Disease Control and Prevention (United States). Immunization Schedules 2020. https:// www.cdc.gov/vaccines/schedules/index.html. Accessed 16 Apr 2020.

76. Federal Public Service Health FCSaE. VACCINATION DE L'ENFANT \& DE L'ADOLESCENT. 2019; https://www.health.belgium.be/sites/default/files/ uploads/fields/fpshealth_theme_file/css_9485_ vaccination_contre_le_meningocoque_update.pdf. Accessed 16 Apr 2020.

77. World Health Organization. WHO vaccine-preventable diseases: monitoring system. 2019 global summary. 2020. https://apps.who.int/immuiza tion_monitoring/globalsummary/schedules?sc\%5B r\%5D $\% 5 \mathrm{~B} \% 5 \mathrm{D}=\mathrm{AFRO} \& \mathrm{sc} \% 5 \mathrm{Br} \% 5 \mathrm{D} \% 5 \mathrm{~B} \% 5 \mathrm{D}=\mathrm{AMR}$ O\&sc $\% 5 \mathrm{Br} \% 5 \mathrm{D} \% 5 \mathrm{~B} \% 5 \mathrm{D}=\mathrm{EMRO} \& \mathrm{sc} \% 5 \mathrm{Br} \% 5 \mathrm{D} \% 5 \mathrm{~B}$ $\% 5 \mathrm{D}=\mathrm{EURO} \& \mathrm{sc} \% 5 \mathrm{Br} \% 5 \mathrm{D} \% 5 \mathrm{~B} \% 5 \mathrm{D}=\mathrm{SEARO} \& \mathrm{sc} \% 5$ $\mathrm{Br} \% 5 \mathrm{D} \% 5 \mathrm{~B} \% 5 \mathrm{D}=\mathrm{WPRO} \& \mathrm{sc} \% 5 \mathrm{Bd} \% 5 \mathrm{D}=\& \mathrm{sc} \% 5 \mathrm{Bv} \%$ $5 \mathrm{D} \% 5 \mathrm{~B} \% 5 \mathrm{D}=\mathrm{MENACWY}-135+\mathrm{CONJ} \& \mathrm{sc} \% 5 \mathrm{Bv} \%$ 5D $\% 5 \mathrm{~B} \% 5 \mathrm{D}=\mathrm{MENACWY}-135+\mathrm{PS} \& \mathrm{sc} \% 5 \mathrm{BOK} \% 5 \mathrm{D}=$ OK. Accessed 16 Apr 2020. 